\title{
ORIENTAÇÕES CURRICULARES E FORMAÇÃO CONTINUADA: SILENCIAMENTO DO PROFESSOR
}

\author{
Valda Inês Fontenele Pessoa ${ }^{1}$
}

\begin{abstract}
RESUMO
Este trabalho apresenta resultados de uma pesquisa realizada com docentes de escolas do município de Rio Branco-Ac, objetivando identificar e analisar os contornos e pressupostos da formação continuada de professores, implementada pela Secretaria de Estado de Educação/Secretaria Municipal de Rio Branco, a partir de 2008, com a elaboração dos Cadernos de Orientação Curricular e a formação dos professores, a partir desse material. Adotou-se, nesta pesquisa, uma abordagem qualitativa, para a qual foram utilizados análise documental, vídeos de reportagens e três grupos focal. Constituem-se, como base teórica, autores como Almeida (2011), Ball (2002), Aplle (2006) e Popkewitz (1997). Observou-se que a concepção que orienta a formação continuada de professores tem características gerencialistas e performáticas. Esse modelo de formação é centrado na figura do professor de forma isolada do contexto em que trabalha, pressupondo que pouco ou nada têm a dizer sobre o que é necessário para robustecer a sua formação e que isso compete a outros, ressignificando, assim, o que é ser professor. Evidencia-se o entendimento de que o ensino é uma ciência aplicada e que os conhecimentos necessários para o sucesso profissional do professor já foram produzidos cientificamente por pesquisadores da educação, restando absorvê-los e aplicá-los de forma adequada.
\end{abstract}

PALAVRAS-CHAVE

Currículo. Formação Continuada. Professores.

\section{INTRODUÇÃO}

Este texto ${ }^{2}$ traz parte dos resultados de uma pesquisa, concluída no ano de 2013, com professores de escolas do município de Rio Branco-Ac, com o objetivo de identificar e analisar os contornos e pressupostos da formação continuada de professores, implementada pela Secretaria de Estado de Educação e Esportes/Secretaria Municipal de Rio Branco. Para isso, foi feito um recorte da formação continuada desencadeada a partir de 2008, quando o Ministério da Educação - MEC, pactuou com os entes federados o compromisso Todos pela Educação, que culminou, no município de Rio Branco, com a elaboração dos Cadernos de Orientação Curricular e a consequente formação continuada dos professores, a partir daquele material, sob a responsabilidade de um instituto não governamental, domiciliado fora do Estado do Acre, contratado para essa finalidade.

Assim, a presente investigação buscou trilhar as marcas deixadas pela política nacional de educação implementada pelo Estado Avaliador e as consequências desse modelo para a formação continuada de professores. É uma abordagem qualitativa, para a qual foram

\footnotetext{
${ }^{1}$ Doutora em Educação (PUC-SP, 2011) e Professora do Centro de Educação, Letras e Artes da Universidade Federal do Acre (UFAC).

${ }^{2}$ Originariamente apresentado na forma de comunicação oral durante o VIII Simpósio Linguagem e Identidade da/na Amazônia Sul-Ocidental: Artes, silêncios e silenciamentos e VII Colóquio Internacional "As Amazônias, as Áfricas e as Áfricas na Pan-Amazônia”, no campus da UFAC, em 2014.
} 
utilizados análise documental, vídeo de reportagem ${ }^{3}$ que demonstram como vem acontecendo a formação de professores e grupo focal em três momentos, com diferentes grupos. Parte da coleta de dados aconteceu em ambientes fora do local de trabalho, com professores que atuam no primeiro segmento do Ensino Fundamental de escolas do município de Rio Branco. Os grupos foram constituídos de seis, sete e seis profissionais, cada um deles, oriundo de uma escola diferente.

Para o início da conversa, houve as apresentações de praxe e a busca de uma atmosfera agradável e descontraída, para favorecer a conversa que vinha a seguir. Solicitou-se que falassem um pouco do ambiente de trabalho na escola, como estavam desenvolvendo as suas aulas, se estavam estudando e que cursos haviam realizado após a conclusão da formação superior. Após todas emitirem suas considerações, acerca do que havia sido perguntado, centrou-se o foco nos últimos encontros de formação promovidos pela Secretaria Municipal de educação - SEME. Cada reunião de grupo focal teve uma duração de duas horas e meia, em média.

Os encontros foram gravados em três aparelhos de áudio, distribuídos entre os participantes, com o auxílio de dois bolsistas de iniciação à pesquisa. As gravações foram transcritas e organizadas de acordo com as abordagens desenvolvidas, tendo o cuidado de marcar aspectos congruentes, divergentes e contraditórios dentro de uma mesma fala, para que fosse possível a sistematização e a análise dos principais achados.

\section{O QUE TEM SIDO DITO PELA PERSPECTIVA CRÍTICA DE CURRÍCULO?}

O significado de currículo, representando projeto de escolarização, tem se alterado semanticamente no decorrer dos tempos, representando desde um entendimento restrito de planificação da instrução até uma compreensão de projeto de formação aberto, flexível e imprevisível, no contexto organizacional e fora dele. Mesmo estando consciente de outras perspectivas e principalmente da vitalidade das análises referenciadas nos estudos pósestruturalistas, optou-se por não abordá-las, centrando o foco na escola crítica de currículo.

Os anos 70 do século XX significou uma reviravolta para a educação, com a emergência de diferentes paradigmas de pensamento. Houve movimentos de crítica e renovação em várias partes do mundo. As críticas radicais desenvolvidas por esses movimentos à educação liberal

\footnotetext{
${ }^{3}$ Vídeo de reportagem presente no YouTube sobre ações do Instituto Abaporu no Acre, publicado em 27/04/2012. https://www.youtube.com/watch?v=aPaDN iAOg
} 
e, em especial, aquelas traduzidas por Althusser e Bourdieu, vão dar sustentação ao pensamento de Apple (2006) ao elaborar uma análise crítica do currículo.

Althusser (1985) assevera que a escola contribui diretamente para a reprodução da sociedade capitalista, enquanto permanecerem os mecanismos de reprodução estrutural e econômica, ao transmitir, por meio dos conteúdos escolares, as crenças que fazem ver os arranjos sociais existentes como bons e desejáveis. Embora Apple (2006), tenha como ponto de partida o pensamento de Althusser (1985), diferentemente desse pensador, vai ressaltar que a vinculação entre economia e educação não se estabelece de modo automático e direto. Essa relação é mediada por processos produzidos pela ação humana no ambiente educacional e no interior do currículo. Chama a atenção, nesse sentido, para o fato de que a reprodução social não é um processo garantido.

Reconhece, ainda, a possibilidade do surgimento, nesse local, do conhecimento até então inexistente, negando dessa maneira que o espaço educativo institucionalizado detenha apenas a dimensão reprodutora do conhecimento já produzido em outro lugar, como afirmava Althusser (1985).

No mesmo contexto de Michael Apple, surge Giroux (1986) para contribuir e delinear a corrente do pensamento crítico de currículo. Na primeira fase de sua teorização, compreende o currículo por intermédio dos conceitos de emancipação e libertação. Afirma que é por meio do processo pedagógico de resistência que as pessoas podem tomar consciência do papel de controle e poder exercido pela escola e pelas estruturas sociais, que elas podem emancipar-se e libertar-se desse mesmo poder e controle. Os conceitos de "esfera pública, intelectual transformador e voz" estabelecem o contorno da sua concepção de currículo emancipador ou libertador. Segundo ele, a escola e o currículo devem ser concebidos como uma esfera pública democrática, na qual alunos, professores e todos que ali convivam possam exercer e desenvolver as habilidades da discussão, da participação e do questionamento.

Nesse processo, o professor deixa de exercer apenas a função de técnico especializado no contexto da burocracia central ou escolar para passar a desempenhar o papel de intelectual transformador, em que se mantém permanentemente envolvido no processo de construção da emancipação e libertação, combinando reflexão e prática a serviço da educação dos estudantes, para que se tornem cidadãos reflexivos e ativos. Para ele, é essencial tornar o pedagógico mais político e o político mais pedagógico. Tornar o pedagógico mais político significa colocar a escolarização na esfera política. Nessa perspectiva, a reflexão e a ação 
críticas passam a fazer parte do projeto social, na medida em que os alunos são inseridos, de forma confiante, no processo de combate das injustiças econômicas, políticas e sociais e, nessa luta, humanizam-se cada vez mais. Tornar o político mais pedagógico significa, por sua vez, a utilização de pedagogia que trate os aprendizes como agentes críticos, que tornem os conhecimentos problematizados e utilizem o diálogo crítico e afirmativo, que argumentem a favor de um mundo qualitativamente melhor para todos. Ele vê a pedagogia e o currículo por meio da noção de "política cultural”. No interior do currículo constroem-se significados e valores culturais. Diversa da perspectiva da racionalidade técnica, a abordagem desse pensador compreende o currículo como um espaço em que ativamente se produzem e se criam significados sociais que estão em permanente disputa e não somente como um processo de transmissão de fatos e de conhecimentos objetivos. Os significados criados são impostos, mas também contestados.

\section{OS PROFESSORES NO CONTEXTO DO CURRÍCULO ENQUANTO POLÍTICA PÚBLICA}

Ao analisar as reformas educacionais do seu país, a cerca de três décadas atrás, Giroux enfatizava que o apelo por mudança que passavam era desanimador e apresentava aos professores desafios nunca antes imaginados. Acusava que os reformadores, que lideravam a série de reformas no âmbito da educação, desconfiavam da capacidade intelectual dos professores das escolas públicas, uma vez que os ignoravam e pouca importância era dada ao papel que vinham desenvolvendo na formação dos alunos. Salientava que quando ocorria a convocação dos professores era para entrarem num debate tardio que os submetia a um reduzido status técnico para o cumprimento de determinações decididas por especialistas distantes da escola e dos acontecimentos diários vivenciados no cotidiano do espaço público escolar.

Por outro lado, afirmava ser o momento oportuno para desencadear um debate público sobre a natureza da crise educacional, esta com profundas raízes ramificadas pelo processo incessante de enfraquecimento e silenciamento dos professores em todos os níveis da educação. Paralelamente ao debate público, dizia que o momento ensejava também a oportunidade de se "engajarem em uma autocrítica muito necessária em relação à natureza e finalidade da preparação dos professores, dos programas de treinamento no trabalho e das formas dominantes da escolarização" (GIROUX, 1997, pp. 156-157). 
Para Giroux era imperioso analisar as forças motrizes que têm impulsionado as mudanças, bem como analisar os materiais produzidos conjuntamente com os currículos, que corroem e reduzem a formação, levando ao que ele denomina de proletarização do trabalho docente. Essas têm sido chaves importantes para colocar em aberto a tendência letal que reduz, silencia e reforma o professor ao simples status de técnico especializado dentro da burocracia estatal, mudando essencialmente o significado de ser professor. Ressaltava que no centro das ideologias que advogam a favor dos aspectos instrumentais e pragmáticos do fazer docente, estão: a ideia da separação entre quem concebe e quem executa a ação; o enquadramento dos conhecimentos curriculares para melhor gerenciá-lo e avaliá-lo; e a depreciação das ações desenvolvidas por professores e alunos que demonstram capacidade crítica e intelectual e a supervalorização das ações práticas.

Imbricada a essa racionalidade, segundo Zeichner (1992), está presente uma concepção de ensino como ciência aplicada, que acredita que a investigação educacional já produziu conhecimentos que permitem oferecer o escopo necessário para a tomada de decisões e reformulação dos currículos pouco flexíveis de formação de professores, de tal forma, que abarca detalhada e sistematicamente os níveis de conhecimento, de competências e das estratégias a serem buscadas no processo de ensino e aprendizagem. Ele reconhece que as produções acadêmicas têm conseguido avanços significativos, que devem ser buscados para alimentar a formação inicial e continuada, do que ele chama de practicum dos professores, mas adverte sobre os seus limites e possibilidades. Ressalta, principalmente, o aspecto de carregarem consigo, na maioria das vezes, o estigma de superioridade em relação às outras formas de conhecimento.

Ao tomar esse conjunto de pressupostos como orientadores das políticas públicas educacionais, o Ministério de Educação e as Secretarias de estados brasileiros, minam sutilmente os esteios mestres que sustentam a concepção do que é ser professor em uma visão mais ampla. Perdem-se de vista os processos contínuos de formação que refletem sobre os princípios que estruturam a vida e prática em sala de aula; perdem-se as oportunidades de envolvê-los ativamente na produção de materiais curriculares coerentes com o meio cultural e social, dos quais fazem parte; perdem-se as oportunidades de, coletivamente, examinarem a natureza subjacente dos problemas escolares e de desenvolverem os seus potenciais de questionamento, de elaborarem perguntas em torno do trabalho que realizam, de ampliarem cotidianamente o horizonte intelectual. 
É mais racionalizado operar, embora erroneamente, com o pensamento de que todos têm a possibilidade de aprender a partir dos mesmos métodos, técnicas, estratégias e materiais de ensino. A lógica que entende que os alunos têm culturas e talentos diferentes, e por assim ser, significam também de forma diferente, é desconsiderada pelas posturas gerencialistas e performáticas (BALL, 2002). Tomar aquela lógica como parâmetro para embasar as políticas públicas em educação é extremamente incongruente com os pressupostos que sustentam o capital, ao qual o processo de escolarização está conectado e a seu serviço.

O ponto nevrálgico de todo o arcabouço dessa corrente de pensamento é o desserviço que efetivamente prestam à formação de professores, como uma erva daninha que se alastra por todo o ocidente e, em especial, em todo território brasileiro, pois é este ideário, travestido de outras linguagens ressignificadas, que passa a fazer parte do imaginário dos profissionais da educação, diminuindo, de forma permitida, a autonomia frente ao trabalho que desenvolvem. Portanto, é essa subjetividade que está sendo construída e as expectativas que se esperam dele.

Popkewitz (1997) denomina esse processo de transmutação de significados dos termos, presentes no tecido social, de epistemologia social. Explica que, no setor educacional, para efetivamente possibilitar o controle das políticas públicas, são utilizados conceitos constitutivos dos saberes da escolarização e os define como elementos da prática institucional, dando-lhes coerência e credibilidade.

É importante perceber que os pressupostos embutidos na epidemia de reformas educacionais, que alastram o mundo, são os mesmo. Ball denomina essa estratégia tecnológica de performatividade. Em suas palavras, a seguir, esse conceito é explicitado:

\footnotetext{
É uma tecnologia, uma cultura e um modo de regulação que se serve de críticas, comparações e exposições como meios de controle, atrito e mudança. Os desempenhos (de sujeitos individuais ou organizações) servem como medidas de produtividade e rendimento, ou mostras de "qualidade" ou ainda "momentos" de promoção ou inspeção. Significam, englobam e representam a validade, a qualidade ou o valor de um indivíduo ou organização dentro de um determinado âmbito de julgamento/avaliação (BALL, 2002, p. 4).
}

Nesse novo contexto, criado pelas reformas, a avaliação alçou um patamar central. $\mathrm{O}$ papel do Estado é reconfigurado, passando a ser o avaliador por meio do Sistema Nacional de Avaliação. Nesse realinhamento, é construído um aparato para dar a impressão de maior liberdade e flexibilidade nas ações de escolarização, tanto nos aspectos procedimentais, quanto financeiros, principalmente no que diz respeito aos gestores das organizações 
escolares. Eles são motivados a trabalharem com dados estatísticos, a partir dos resultados numéricos alcançados periodicamente. Nesse quadro, os professores são chamados a refletirem sobre os resultados que conseguiram alcançar, ou melhor, "fazem cálculos sobre si próprios, "acrescentam valor" a si próprios, aumentam a sua produtividade, vivem uma existência baseada em cálculos" (BALL, 2002, p. 6).

Essa tecnologia engendra um conjunto de aspectos combinados e articulados entre si, como: recompensas de acordo com o desempenho, estabelecimento de metas, geração de discursos e a comparação sistemática entre pessoas e entre organizações escolares. Com essas provocações, é inevitável o replanejamento institucional. Novos desenhos disciplinares são postos pela competição, eficiência e produtividade e consequentemente, outras configurações éticas passam a vigorar, fundamentadas no autointeresse institucional, pragmatismo e valor performático.

As práticas de ensino, a subjetividade docente, as relações sociais e interpessoais, no contexto dessas reformas, estão diametralmente modificadas. O trabalho é impulsionado pela maximização dos coeficientes numéricos de cada um. Os maiores propósitos giram em torno das metas que devem atingir, dos dados que precisam compor, dos encontros de avaliação e inspeção que irão participar, dos prêmios e recompensas que desejam alcançar. Tais resultados são publicamente devassados e comparados. As autênticas relações sociais e interpessoais são substituídas por relações de julgamento. Todos são olhados e valorizados, única e exclusivamente pela sua produtividade. E é dessa forma que os sujeitos envolvidos correm competitivamente atrás dos maiores resultados quantitativos, de maneira a demonstrar as suas realizações. Como se vê, as reformas têm o poder de carregarem consigo uma dimensão racional objetiva e uma dimensão emocional.

Ball, fundamentado em Lyotard (1984), afirma que todo o dispêndio de energia para atingir a informação performativa, inviabiliza aprofundamentos que lhes façam, de fato, evoluir intelectualmente na compreensão dos fenômenos no contexto do seu trabalho e do seu tempo de forma ampla e verdadeiramente com liberdade. Para ele, a identidade de professores vai se constituindo muito mais por mecanismos de projeção do que mesmo por mecanismos de introjeção. O que ética e introspectivamente se avalia como mais próximo e mais apropriado para um dado contexto, são desvirtuados pelas exigências externas. Objetivos pessoais e profissionais são deixados à margem. O empenho profissional é substituído pelo que dará o resultado esperado. Assim como a organização educativa é reformada, o conceito 
do que é ser professor também é reformado, alterando substancialmente o seu significado e, consequentemente, o que esses docentes vão buscar na formação continuada.

\section{O QUE PESQUISADORES TÊM DITO SOBRE FORMAÇÃO CONTINUADA}

Segundo Almeida (2011) são duas as principais abordagens de formação continuada de professores: uma centrada no professor e outra centrada no desenvolvimento das equipes escolares e da escola. Na primeira abordagem, centrada no professor, se destacam três abordagens: $1^{\mathrm{a}}$ - como desenvolvimento de características éticas e políticas; $2^{\mathrm{a}}$ - como necessidade de suprir déficits da formação inicial; e $3^{\text {a }}$ - como um empreendimento de cunho pessoal. Na primeira e na terceira são investimentos de cunho pessoal, diferindo-se por se tratar, na primeira, de projeto de construção subjetiva e profissional que se dá por escolha necessária para dar sentido e valor tanto às atividades técnicas da docência, como a ética, a política e o aspecto emocional. Já a terceira, visualiza mais o ciclo de vida profissional, acreditando que conhecer os estágios que fazem parte da carreira docente possibilita destacar necessidades e carências dos professores, nas fases em que estão vivenciando. A segunda surge com a concepção de preenchimento dos vácuos deixados pela formação inicial e, por essas razões, é chamada de abordagem do déficit. Vê o professor como incapaz de perceber necessidades para desenvolver e fortalecer-se enquanto profissional. As definições e estratégias de formação continuada são realizadas em outros espaços e níveis hierárquicos superiores aos quais vivenciam esses profissionais. Alheios à diversidade dos contextos de escolas, alunos e professores, propostas de formação são planificadas e implementadas, desvinculadas das características e interesses das pessoas as quais elas se destinam.

$\mathrm{Na}$ segunda abordagem, centrada no desenvolvimento das equipes escolares e da escola, dois grupos de atuação são percebidos nessa abordagem. Um delega ao coordenador pedagógico a liderança para articular o conjunto de professores de cada escola, objetivando a efetivação do processo de formação continuada da equipe. As ações da figura do coordenador pedagógico são ampliadas, passando a ser o grande responsável pela dinamização da organização coletiva de quatro aspectos importantes do funcionamento da escola: coordenar o trabalho pedagógico; identificação de demandas e necessidades de formação; intermediar a formação continuada; e mobilizar o conjunto de profissionais para elaborar/reelaborar o Projeto Político Pedagógico da escola. 
Outro entende a escola como um lócus permanente de formação continuada para todos. Estão presentes nesse espaço preocupações como possibilitar clima interativo e colaborativo, desenvolvimento do coletivo, busca de apoio externo de acordo com necessidades. Admitem e veem como necessidade de todos a realização de questionamentos frequentes sobre o trabalho que desenvolvem. Ainda de acordo com Almeida, os professores que trabalham orientados por essa perspectiva "reúnem-se para estudar, para fazer análise curricular e propor modificações nos conteúdos trabalhados em cada ano e nível, para elaborar e realizar pesquisas e avaliações internas e assim por diante" (ALMEIDA, 2011, p. 5).

Essa vertente cultiva também o propósito de, cotidianamente, elegerem temáticas que promovam discussões entre os membros do grupo, acerca dos aspectos que vão visualizando sobre a profissão docente, como também, motivam-se coletivamente a testar diferentes estratégias de ensino, sempre voltados para uma melhor organização do processo didático. Tão importante quanto todos esses fatores referidos, são os cuidados tomados para que o processo de discussão e reflexão seja capaz de proporcionar um clima de entrosamento e confiança entre os pares, em diferentes estágios de experiência, nível e área de atuação.

\section{OS CADERNOS DE ORIENTAÇÃo CURRICULAR E A FORMAÇÃo CONTINUADA DOS PROFESSORES}

Em 2008, o Ministério da Educação pactuou com os entes federados o compromisso Todos pela Educação. No mesmo ano, a Secretaria de Estado de Educação e Esporte do Acre em parceria com a Secretaria Municipal de Educação de Rio Branco publicam os dois primeiros manuais de uma série de oito que passaram, a partir de então, a orientar a formação continuada dos professores e a organização do trabalho pedagógico do primeiro segmento do Ensino Fundamental do município.

No ano seguinte, os outros seis manuais são publicados, fechando a série de orientações do Ciclo inicial ao quinto ano. Esse material foi produzido por uma Organização não governamental, contratada pela Secretaria de Estado de Educação e Esporte do Acre para essa finalidade. A empresa tem domicílio fora do Estado do Acre e da região norte, mas contrata os seus serviços para as outras regiões do país.

Os oito Cadernos de Orientação Curricular - COC mantêm o mesmo formato, diferenciando-se apenas pelas especificidades e conteúdo das áreas. Cada volume é aberto com a fala do ocupante do cargo de Secretário de Estado de Educação. Na sequência, com o 
subtítulo "Cadernos para o professor", constam explicações acerca do conjunto dos manuais que compõem a série, seguidas pela introdução denominada “A importância do conhecimento didático". Em quatro linhas, são explicitadas as dimensões filosófica, social e política da profissão docente para, posteriormente, no restante da introdução e de todos os outros tópicos, focar três eixos: "conhecimento amplo dos conteúdos a serem trabalhados; processos de desenvolvimento e de aprendizagem dos alunos e mediação didática". Ainda na introdução, fica bem exposta a concepção que orienta a formação continuada de professores:

Como sabemos, hoje, a educação básica e a formação inicial dos profissionais da
educação em nosso país, em geral, não garantem o conhecimento necessário para o
adequado exercício do Magisterio - todos esses saberes acima relacionados. (sic)
Também em outros campos de atuação os profissionais não saem dos cursos de
habilitação completamente preparados - mas o fato é que, no caso da educação, há
muitas lacunas deixadas pela formação inicial que precisam depois ser resolvidas ou
minimizadas de algum modo quando os educadores (...) já estão atuando junto aos
alunos (ACRE, 2008, p. 11).

Como é possível observar, a concepção que orienta essa formação continuada de professor é aquela que Almeida denominam de abordagem do déficit e é centrada na figura do professor de forma isolada do contexto em que ele trabalha. Esses autores também afirmam que essa compreensão pressupõe que os professores pouco ou nada têm a dizer sobre o que é necessário para robustecer a sua formação e que isso compete a outros, localizados em níveis hierárquicos superiores, ou seja, às Secretarias de Educação. Acrescentam, ainda, que estas propostas tendem a ser iguais, do tipo "tamanho único e unissex", tendo em vista que trabalham para atingir metas de formação de um maior número de professores, sem muitas preocupações com as peculiaridades e motivações dos grupos constitutivos de cada instituição escolar.

Evidencia-se, também, nessa concepção, o entendimento de que o ensino é uma ciência aplicada e que os conhecimentos necessários para o sucesso profissional do professor já foram produzidos cientificamente por pesquisadores da educação, restando absorvê-los e aplicá-los de forma adequada. É importante ressaltar, que essa mesma ciência educacional já apresenta subsídios sólidos sobre a insuficiência dessa compreensão, mas que pouco é levado a termo.

É com essa concepção que o Instituto vem, desde 2008, desenvolvendo cursos de formação continuada, com carga horária restrita, uma média de dezesseis horas, por módulo, que acontecem em momentos diferentes, em períodos de um a dois dias. Esses módulos de curso têm como base os cadernos de orientação curricular e são ilustrados com os nomes: 
"Como ensinar os alunos a estudarem; Como ensinar avaliar diferentes tipos de conteúdos; e Como aprofundar a questão da avaliação com oficina de montagem de avaliação". Os cursos são ministrados por professores de outras regiões e que pouco conhecem das peculiaridades locais, dos professores e alunos que nessa região habitam. Veja-se o que foi divulgado nos veículos de comunicação: “Os professores do Instituto (...) ministram as aulas e capacitam os professores para favorecer a aprendizagem em todas as disciplinas e o enfoque é o ensino específico de cada disciplina" (Vídeo de reportagem no You Tube, 2012).

Também participam desses cursos membros das equipes centrais da secretaria municipal e, quanto a essa participação, indicam ter objetivos bem claros: "A gente acompanha o planejamento e depois vê com os coordenadores das escolas como está se dando o que foi pensado aqui e lá dentro da sala de aula” (Vídeo de reportagem no You Tube, 2012).

A mesma reportagem que focaliza a formação continuada de professores entrevista uma diretora de escola, a respeito das suas impressões acerca dos cursos direcionados aos professores. Segundo essa gestora esses cursos são bons, mas "A gente percebe que eles deixam muito a desejar ainda, mas a gente já percebe que, principalmente através até das avaliações externas, que estas capacitações já contribuíram bastante para a melhoria da qualidade do nosso ensino" (Vídeo de reportagem no You Tube, 2012).

Há nas entrelinhas da fala da gestora que aparece no vídeo uma convicção de que aqueles cursos não vão ao encontro da realidade vivenciada nas escolas por alunos e professores, entretanto, afirma que apesar de não atingir plenamente os desejos de formação manifestos, vêm dando resultado nas avaliações externas e isso tem demonstrado melhoria da qualidade do ensino. Nessa fala está explícito o que estes cursos vêm proporcionando na vida das escolas e principalmente na vida profissional docente. A performática é o relevo maior. Apresentar resultados "convence" a quem tem de ser convencido. É extremamente difícil trabalhar diferente e não apresentar o que é desejável, expresso nos matérias curriculares, mesmo que se apresentem justificativas plausíveis quanto ao tempo de cada um e à diversidade cultural da qual, hoje, a escola está povoada.

Nos encontros proporcionados pelos três grupos focais com as professoras que participam efetivamente desses cursos, foram expressas, recorrentemente, impressões que giram em torno das falas apresentadas a seguir:

Os cursos são importantes, nós aprendemos muito, mas às vezes fica confuso... as crianças precisam de muitas outras coisas que não temos condições de parar para atender. Só sei que é muito difícil... (professora 3, grupo focal 1) 
Como não gostar desses cursos, se eles ensinam o passo-a-passo? Além disso, facilita muito a nossa vida e ainda os meninos estão se saindo melhor nas provinhas externas, que é o mais importante (professora 7, grupo focal 2).

As vezes me dá muito tédio, quando vou para esses cursos... muitas coisas já vimos na faculdade e não tem dado certo. Cheguei a uma conclusão, o que dá resultado é repetir, repetir e deixar eles brincarem um pouco (professora 5, grupo focal 3).

E assim vão construindo as suas subjetividades e os seus afazeres docentes na escola. $\mathrm{O}$ processo de descrença vai sendo instalado. Seguem cumprindo o estabelecido, mesmo sem expectativas. Sabem que lhes falta muito. Não há o que se questionar, quanto à formatação técnica e construtivista dos cadernos curriculares. Representam, classicamente, o que Bobbitt (1971) e Tyler (1974) e seus seguidores orientam, mas também e, contraditoriamente, inserem nesse contexto orientações importantes de Piaget e Vigotsky, traduzidas por outros autores, constantes da bibliografia lá referida. Avançaram muito em relação a outros materiais já produzidos anteriormente. A palavra de ordem é a eficiência. Apresentam os aspectos nucleares e interdependentes do currículo: objetivos-conteúdos-atividades-recursos-avaliação, como ainda, os aspectos psicossociais que delimitam a abrangência das tomadas de decisões. Também são destacados aspectos técnico-profissionais articulados com a metodologia e modos operacionais do currículo. Ressalta aos olhos, em todos os volumes, quadros longos e bem detalhados de o que, como ensinar e avaliar. Com as políticas públicas deterministas que sustentam e financiam esse trabalho, presume-se ter sido impossível ir além do que foi apresentado. Seria extremamente incongruente com o que está nacionalmente acordado e pactuado.

Sobre esse aspecto, Apple (2006) assinala que o campo social - e nele está inserida a educação - é um campo contestado em que os grupos sociais dominantes recorrem constantemente a estratégias de convencimento, em que a dominação econômica pode transformar-se em dominação cultural. A eficácia dessas estratégias é atingida quando são naturalizadas e passam ao senso comum. Com a visão de Apple, a preocupação, que na perspectiva técnica é centrada nos aspectos técnicos de "como" elaborar o currículo, deslocase para entender como certos conhecimentos são considerados legítimos e outros, ilegítimos. A perspectiva postulada por Apple passa, nesse sentido, a preocupar-se com o "por que" em torno do currículo.

Frente as condições que cercam a carreira docente atualmente no país, pressionados pelas avaliações externas e pela performance que a escola e ele precisam apresentar, o professor que recebe esse material, mesmo estando lá expresso que as "propostas e exemplos 
contidos nos cadernos são apenas referências que cabe às Secretarias de Educação" (Acre, 2008, p.13) fornecer e, ainda mais, vivenciando as atividades dos cursos que lhes são apresentados, fica longe a possibilidade de uso do material como fonte de pesquisa, de comparação e de escolha para a sua atuação e desenvolvimento pessoal e profissional.

Dessa forma, operar ativa e coletivamente na esfera pública da escola, transformando-a e se constituindo intelectual transformador, como defende Giroux, fica muito mais difícil para o professor. Todo esse processo o faz, quando muito, um repetidor eficiente do que lhes mandam executar sem qualquer questionamento. Assim, currículo e formação continuada, no contexto das políticas públicas atuais, se articulam sistematicamente moldando um outro significado do que é ser professor e os silenciando sobre outras possibilidades de atuação.

\title{
CURRICULUM GUIDELINES AND CONTINUING EDUCATION: TEACHER SILENCING
}

\begin{abstract}
This paper presents results of a survey of teachers from schools in the city of White-Ac River, aiming to identify and analyze the contours and assumptions of continued teacher training, implemented by the Ministry of Education / The Municipal Secretary of Education of Rio Branco, from 2008, with the development of the Curriculum Guidance Booklets and teacher training from that material. Is adopted in this study, a qualitative approach, for which we used document analysis, reports and videos focus group. Is constituted as theoretical basis, authors such as Almeida (2011), Ball (2002), Apple (2006) and Popkewitz (1997). It was observed that the design that guides the continuing education of teachers has managerial and performative characteristics. This training model is centered on the teacher figure in isolation from the context in which it works, assuming little or nothing to say about what is needed to strengthen their training and that it is for others, giving new meaning, so what to be a teacher. This study highlights the understanding that education is an applied science and knowledge necessary for professional success teacher have been produced scientifically by researchers of education, leaving absorb them and apply them appropriately.
\end{abstract}

KEYWORDS

Curriculum. Continuing Education. Teachers

\section{REFERÊNCIAS}

ACRE. Secretaria de Estado de Educação do Acre. Gerência Pedagógica e Curricular do Ensino Fundamental. Orientações para o ensino de língua portuguesa e matemática no ciclo inicial. caderno 1. Rio Branco-Ac, 2008.

ACRE. Secretaria de Estado de Educação do Acre. Gerência Pedagógica e Curricular do Ensino Fundamental. Para organizar o trabalho pedagógico no Ciclo Inicial. caderno 2. Rio Branco-Ac, 2008.

ACRE. Secretaria de Estado de Educação do Acre. Cadernos de orientação curricular: Para organizar o trabalho pedagógico no Ensino Fundamental. caderno 2 geral. Rio Branco-Ac, 2009.

ACRE. Secretaria de Estado de Educação do Acre. Cadernos de Orientação Curricular: Orientações curriculares para o ciclo inicial. caderno $1,1^{\circ}$ e $2^{\circ}$ ano. Rio Branco, Ac, 2009. 
ACRE. Secretaria de Estado de Educação do Acre. Cadernos de orientação curricular: Orientações curriculares para o ensino fundamental. caderno1, $3^{\circ}, 4^{\circ}$ e $5^{\circ}$ ano. Rio Branco, Ac, 2009.

ALMEIDA, C. A. et alii. Secretarias de educação e as práticas de formação continuada de professores. In. E-books 34 a Reunião Anual Anped - Educação e Sociedade. Natal, GT-08, Formação de Professores, 2011.

ALTHUSSER, L. Aparelhos ideológicos de estado - notas sobre os aparelhos ideológicos de Estado. 10a ed. Rio de Janeiro: Graal, 1985.

APPLE, Michael W. Ideologia e currículo. Tradução Vinicius Figueira. $3^{a}$ Ed. Porto Alegre: Artmed, 2006.

BALL, S. J. Reformar escolas/reformar professores e os terrores da performatividade. In: Revista Portuguesa de Educação da Universidade do Minho. Braga - Portugal: vol. 15, nº 002, p. 03-23, 2002.

GIROUX, H. A. Teoria crítica e resistência em educação. Petrópolis: Vozes, 1986.

GIROUX, H. A. Os professores como intelectuais: rumo a uma pedagogia crítica da aprendizagem. Porto Alegre: Artes Médicas, 1997.

POPKEWITZ, T. S. Reforma educacional: uma política sociológica - poder e conhecimento em educação. Porto Alegre: Artes Médicas, 1997.

ZEICHNER, K. Novos caminhos para o practicum: uma perspectiva para os anos 90. In. NÓVOA, António. Os professores e a sua formação. Lisboa: Publicações Dom Quixote, 1992.

http://www.institutoabaporu.com.br/ - Acesso em: 10 de agosto de 2013.

https://www.youtube.com/watch?v=aPaDN_iAOg - Acesso em 13 de agosto de 2013.

Data de recebimento: 28/09/2016

Data de aceite: $17 / 11 / 2016$ 